\title{
Experiments to arouse students' interests in physical optics
}

\author{
Kazue Ishikawa
}

Kazue Ishikawa, "Experiments to arouse students' interests in physical optics," Proc. SPIE 3190, Fifth International Topical Meeting on Education and Training in Optics, (8 December 1997); doi: 10.1117/12.294414 1997, Delft, Netherlands 


\title{
Experiments to arouse students' interests in physical optics
}

\author{
Kazue Ishikawa \\ Department of physics Sophia University \\ 7-1 Kiocho, Chiyoda-Ku, Tokyo, Japan. \\ Fax: +81 3 3238-3341 E-mail: kazue-i@hoffman.cc.sophia.ac.jp
}

\begin{abstract}
Two optical experiments, optical sensitometory and spectrograph, are prepared for sophomores majoring in physics. The purpose of the first experiment is to examine the sensitivities and contrasts of photographic films. Students learn a correct development processing method for scientific photography through the experiment. The purpose of the second experiment is to take spectrograms of various light sources. Students obtain knowledge and experimental techniques for spectroscopy using a spectrograph with logarithmic slit.

It is proposed to perform a preliminary experiment. Students will be familiar with experimental operation. Thus the actual experiment can be done-more smoothly by the knowledge of the preliminary experiments. Moreover, students' interest in understanding the actual experiment have increased. In addition, taking pictures by a pin-hole camera has opened students' minds to the world of physics optics.
\end{abstract}

Key Words: pin-hole camera, spectrograph, logarithmic slit, preliminary experiment.

\section{I . INTRODUCTION}

a. Pin-hole camera: Rays of light go through a small hole and project a scenery on a screen. The whole scheme may be easy to understand. But when you actually try to take photographs with this simple device, you may find it a little difficult. If you use the printing paper which can be used under a safe light, you can take photographs without much difficulty.

b. Structure of the pin-hole camera: Its structure is quite simple, so that anyone can make it for himself. The distance between the pin-hole and the printing paper is $55 \mathrm{~mm}$. The diameter of the pin-hole $2 \mathrm{a}=0.34 \mathrm{~mm}$. We used phosphor bronze thin plate with the thickness of $0.05 \mathrm{~mm}$. The body of the camera is made of cross-grain paper of $0.8 \mathrm{~mm}$. The inside of the body is sprayed with black paint beforehand.

c. The best image of pin-hole camera: The best image of the pin-hole camera is taken and examined. According to the text book, the illuminance of the dot image on the axis changes between $A^{\prime 2} \times 4$ and 0 . As shown in Figure 2, the curve reaches its maximum at $z=a^{2 / \lambda}$ and then it decreases along with $z$ and reaches to 0 . If we put our results into the formula and 
compare it with values in the text book.

$$
\begin{array}{ll}
\text { experimental value } \tau=\lambda \mathrm{z} / \mathrm{a}^{2}=1.0467 \\
\text { theoretical value } & \tau=\lambda \mathrm{z} / \mathrm{a}^{2}=0.9999
\end{array}
$$

It is within the range of error.

d. Focal distance of pin-hole camera: If we use the formula; $z=a^{2 / \lambda}=f^{\prime}$, and assume $f$ is the main focus of the pin-hole camera, the focal distance of the camera is $55 \mathrm{~mm}$. If we deal it as an ordinary camera, $\mathrm{F}$ number is

$$
\mathrm{F}=\mathrm{f} / 2 \mathrm{a}=55 / 2 \cdot 0.17=161.2
$$

This value means that the camera is considerably low speed. The exposure time for the outdoor scenery is about $5 \mathrm{sec} \sim 5 \mathrm{~min}$ throughout the four season of a year.

- Illumination of the dotted ima on the axis (intensity of the diffraction image)

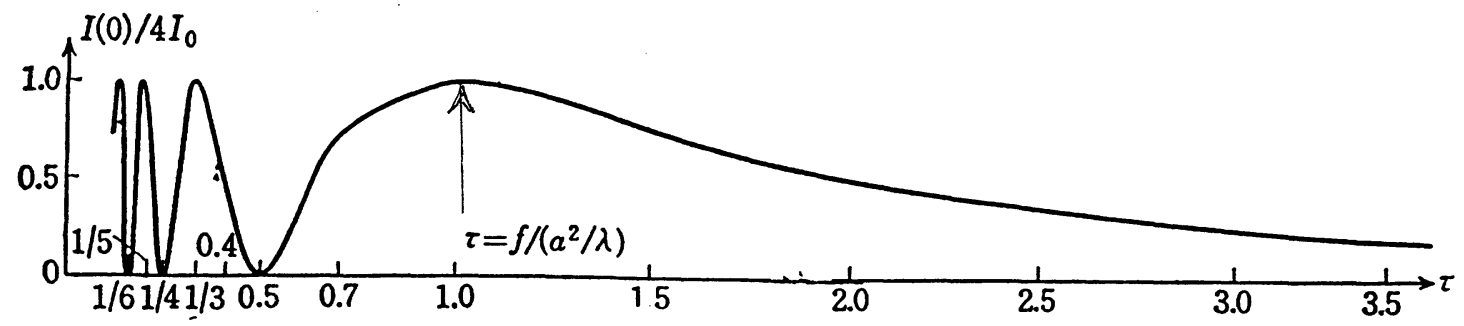

Figure 2

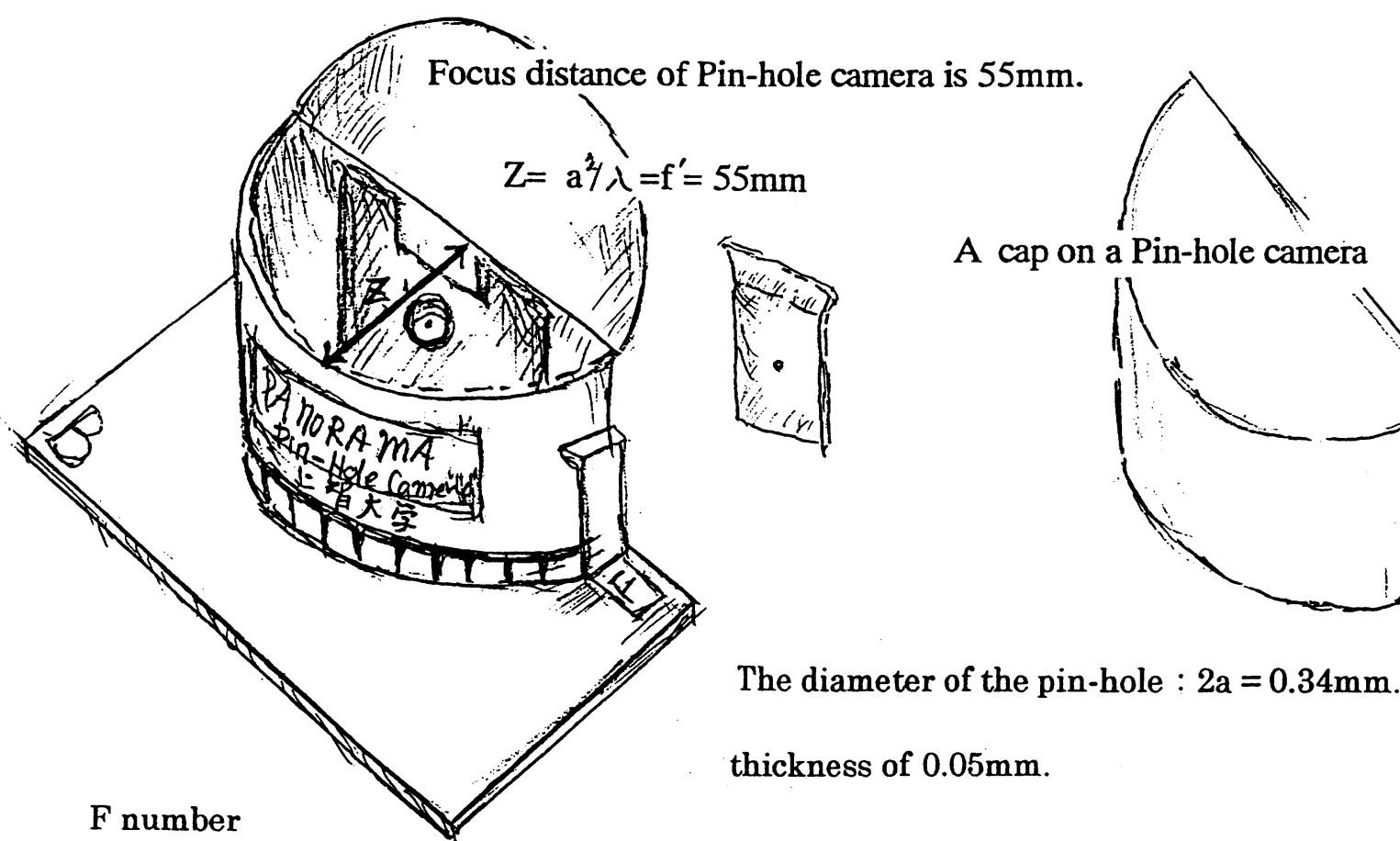

$\mathrm{F}=55 / 2 \cdot 0.17=161.2$ 


\section{EXPERIMENTS AND RESULTS}

experiment: Both sensitometory and spectrograph experiments are conducted in the course for sophomores. Students expose (monochromatic and negative) films through sensitometer's 30 step gray scale, and develop them. Densities of each specific places on the files are measured by a demsitometer. Using the results, students draw characteristic curves to obtain $\gamma$ values (inclination), which would vary according to sensitivities and development time. Thus they can determine the relative degree of contrast of each sample. Three kinds of materials, neopan SS film, mini-copy film and printing paper for enlargement are used. As shown in figure 1, sensitivities and $\gamma$ values can be measured.

In Table 1, we can see that the ISO sensitivity of neopan SS film is actually a little higher than the officially indicate value. Also we can see that the sensitivities of mini-copy film and printing paper are both low, although, in both cases, no ISO values are given. As for $\gamma$ values, they are 0.7 for SS film, 2.1 for mini-copy film, and 1.5 for printing paper. We find that each of the three materials has its own specific characteristics. In a more formal context, it might be necessary to measure the resolutions of the them, but we save time by showing students some examples instead of doing more experiments.

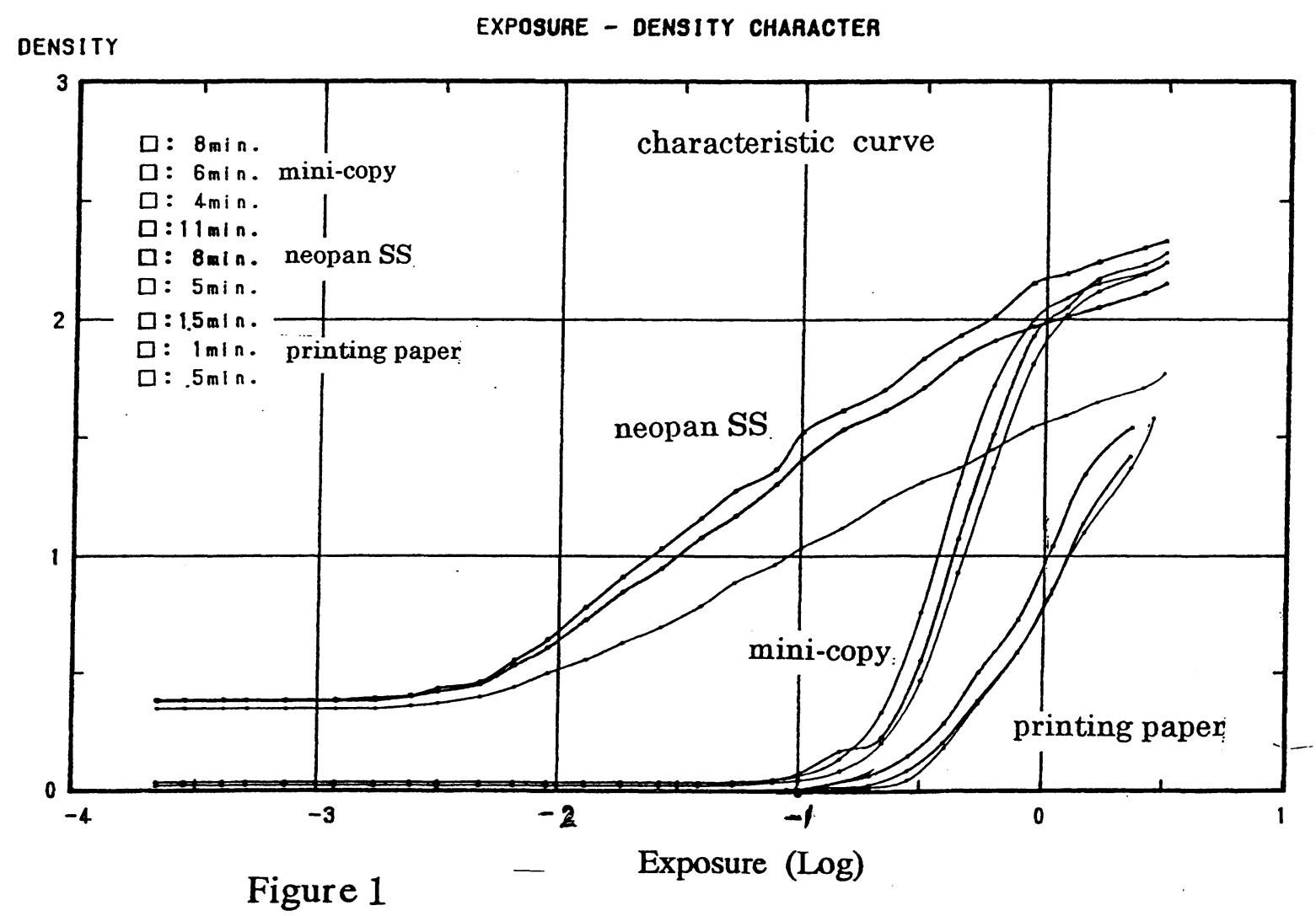




\begin{tabular}{|c|c|c|c|c|c|c|c|c|c|}
\hline & \multicolumn{3}{|c|}{ printing paper. } & \multicolumn{3}{c|}{ mini-copy } & \multicolumn{3}{c|}{ neopan $S S$} \\
\cline { 2 - 10 } & $0.5 \mathrm{~min}$ & $1 \mathrm{~min}$ & $1.5 \mathrm{~min}$ & $4 \mathrm{~min}$ & $6 \mathrm{~min}$ & $8 \mathrm{~min}$ & $5 \mathrm{~min}$ & $8 \mathrm{~min}$ & $11 \mathrm{~min}$ \\
\hline$y$ & 1.13 & 1.05 & 1.07 & 1.76 & 1.78 & 1.26 & 0.34 & 0.31 & 0.36 \\
\hline $\log _{10} \mathrm{X}_{\min }$ & -0.48 & -0.48 & -0.62 & -0.68 & -0.68 & -0.96 & -2.19 & -2.99 & -3.11 \\
\hline$S$ & 3.02 & 3.02 & 412 & 4.79 & 4.79 & 912 & 154 & 977 & 1288 \\
\hline$D_{f}$ & 0.10 & 0.10 & 0.10 & 0.10 & 0.10 & 0.10 & 0.10 & 0.10 & 0.10 \\
\hline
\end{tabular}

\section{Table 1}

Spectrograph experiment: It is to take photographs of the spectra of light from the various sources with a spectrograph (reflection type plane diffraction grating). The educational aim of this experiment is to give students the knowledge and the experimental techniques concerning the spectroscopy. The most important point is to learn how to adjust properly the spectrograph by carefully checking the exact position of the light. Students are expected to think about why there exist such a lot of diaphragms, a shading board, a reflection type diffraction grating, and a lens. First they should figure out the suitable optical position of the source in relation to the incidence slit, taking into consideration the characteristics (external shape) of the light source. This device uses a logarithmic slit, $11.16 \mathrm{~mm}$ in height and $0.005 \mathrm{~mm}$ at the minimum width and $0.64 \mathrm{~mm}$ at the maximum width (cf. the figure). This slit enables us to take photographs very quickly, because we can determine the relative spectrum sensitivity between the light source and exposed material at once.

There are three major methods of illumination.

a. Space brightness method: When the illuminating part of the source is large, the light flux comes evenly, and the source does not emit too much heat, we put the source in front of the incidence slit at an appropriate distance. In this case, the incidence slit is regarded as the secondary source of the light.

b. Incidence slit illumination method of real image type: This method uses a type of convex lens called condenser-lens. Here the image is projected on the incidence slit. For the small source, with the size of less than $1 \mathrm{~mm}$, such as $\mathrm{H}$ type hydrogen electrical discharge tube, this method is effective.

c. Relay-condenser type incidence slit illumination method: When the light source illuminates unevenly, the illumination at the incidence slit would become uneven in proportion to the source. In this case, we put a condenser lens directly before the incidence slit. Using the lens, we project the image not on the incidence slit side but on the diffraction grating. The effectiveness of this method would appear more impressive if we try it after experiencing the irregularity of the spectrum. 


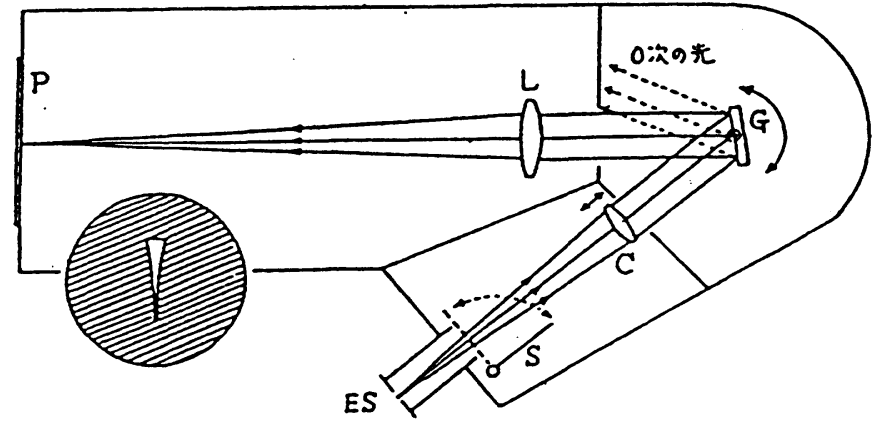

Pattern of Exponential Slit

Figure 3 Spectrograph
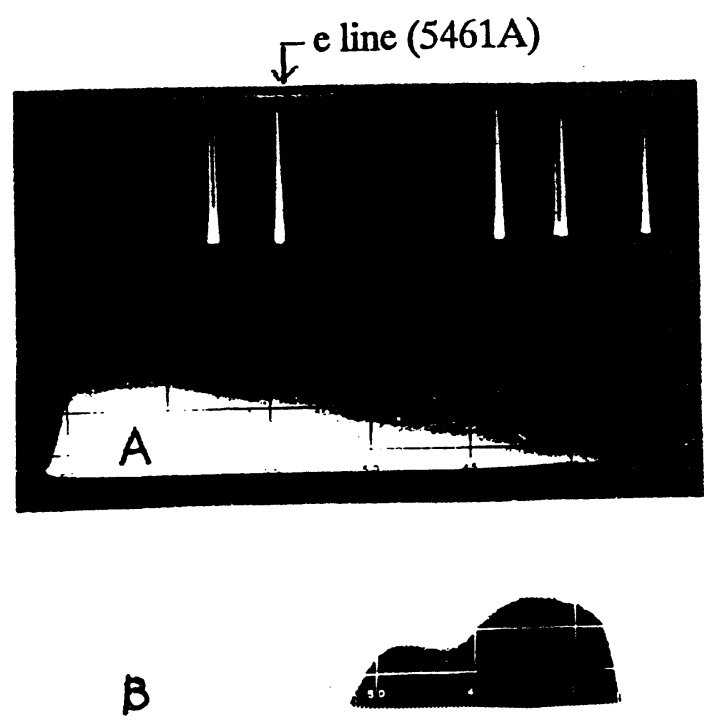

$A=$ neopan SS,B=printing paper . Light=Mercury lamp and Tangusten lamp.

\section{SUMMARY}

In university education, courses, in which the students conduct laboratory experiments by themselves, are really important. Such courses should be carried out with a limited number of students. The small size of the class will ensure the satisfactory level of communication between the teacher and the students. The textbook used in the class should be easy to read. A good textbook can stimulate the curiosity of the students and make them absorbed into the subject with considerable force. What is most important for a teacher is to teach with great zeal. A former president of Sophia University, Fr. Joseph Pittau, once wrote in his book that first of all a teacher should learn the names of the students by heart. I always put this advice in mind when I teach experimental courses. What I think is really important in experimental courses is this: first, the students should make something with their hands, then they should be given a superb textbook, and a teacher who would teach and guide them with considerable zeal.

Finally, I would like to emphasize that every effort is needed to make the students experience the real pleasure of optical experiments. 


\section{ACKOWLEDGEMENTS}

The authors would like to thank Dr. S.Tatsuoka, Mr. N.Kinoshita for many helpful discussions and conscientious instructions during the course of the present works.

\section{REFERENCES}

1. Koichi Shimoda, Experiment for Reconsideration of Basic concepts on Electromagnetism \& Optics.

2. Kazue Ishikawa, The efficiency of illumination in optical system. Japan Optics 96 optics union symposium [Kyushu University].

3. Kazue Ishikawa, One idea on the graduation study of optics. 19nd.Optical symposium 21-22 (1994). 